Original Research Paper

\title{
Aplikasi Kolom Kapur Untuk Mengurangi Pengembangan Tanah Ekspansif Di Desa Pengengat Kecamatan Pujut Kabupaten Lombok Tengah
}

\author{
Muhajirah $^{1 *}$, Didi S. Agustawijaya ${ }^{1}$, Ismail H.M. ${ }^{1}$, Shofia R. ${ }^{1}$ \\ ${ }^{1}$ Jurusan Teknik Sipil Fakultas Teknik Universitas Mataram, Mataram, Indonesia
}

DOI: https://doi.org/10.29303/jpmpi.v3i2.527

Sitasi : Munajirah., Agustawijaya. D. S., Ismail, H. M., \& Shofia, R. (2020). Aplikasi Kolom Kapur Untuk Mengurangi Pengembangan Tanah Ekspansif Di Desa Pengengat Kecamatan Pujut Kabupaten Lombok Tengah. Jurnal Pengabdian Magister Pendidikan IPA, 3(2)

\author{
Article history \\ Received: 30 September 2020 \\ Revised: 14 Oktober 2020 \\ Accepted: 19 Desember 2020 \\ *Corresponding Author: \\ Muhajirah, Jurusan Teknik \\ Sipil Fakultas Teknik \\ Universitas mataram, Mataram, \\ Indonesia \\ Email: muhajirah@unram.ac.id
}

\begin{abstract}
The growing population has an impact on the increasing need for housing. A comfortable house can be made if the ground is fine. Pengengat Village in Pujut District has expansive soil which has high swellingshrinkage properties. This activity aims to provide an understanding of the characteristics of expansive soil and how to improve it. This activity is divided into three stages, including: 1) site survey, 2) counseling, and 3) creating a lime column model. The survey results show that people in Pengengat village do not understand the characteristics of expansive soil and they also do not know how to improve the soil phenomenon. The floors and walls of the house were cracked and some were split. Poor drainage conditions also contributed to the damage to their homes. After carrying out these activities, the residents began to understand the characteristics of the expansive soil and how to improve it. We make three lime columns with a diameter of $25 \mathrm{~cm}$ and a depth of $75 \mathrm{~cm}$. The distance between the lime columns is $1 \mathrm{~m}$. For evaluation purposes, we take soil samples from each hole, the soil samples will be tested to determine the level of swelling.
\end{abstract}

Keywords: Expansive Soil, Swelling, Lime Column

\section{Pendahuluan}

$\mathrm{R}$ umah merupakan kebutuhan primer bagi setiap manusia. Setiap manusia membutuhkan rumah yang aman dan nyaman untuk ditempati. Namun, kondisi lingkungan terkadang menjadi salah satu faktor penyebab rumah tidak aman dan nyaman untuk ditempati.

Beberapa penelitian menyatakan bahwa sebagian besar tanah di Kecamatan Pujut Kabupaten Lombok Tengah merupakan tanah ekspansif yang memiliki kembang susut tinggi (Kharvarazy (2010), Wibawa, LM.H. (2013), Anggara, I.P.H., (2014), Fradana, Y. (2014), dan Ramdhani, A. (2014)). Hasil uji sifat fisik menunjukkan bahwa tanah lempung dari desa
Tanak Awu memiliki potensi pengembangan dari tinggi hingga sangat tinggi karena memiliki Indeks Plastisitas $97,35 \%$ dan potensi pengembangan 16,27\%. Kharvarazy (2010) menjelaskan bahwa hasil penyelidikan tanah pada ruas jalan KuripanPenujak didapatkan susunan tanah dasar dari kedalaman 0 sampai dengan $1,5 \mathrm{~m}$ berupa tanah lempung murni berwarna hitam yang berpotensi mengembangnya sangat tinggi, sedangkan pada kedalaman lebih dari 2,0 $\mathrm{m}$ berupa lempung berbutir kasar berwarna keputihan yang berpotensi mengembangnya tinggi hingga sedang.

Tanah lempung ekspnasif merupakan tanah yang memiliki perilaku kembang-susut tinggi. Pada 
kondisi basah atau kadar air tanah tinggi, volume tanah akan mengembang dan saat kondisi kering volume tanah akan menyusut. Tanah lempung ekspansif memiliki sifat tanah yang kurang baik seperti plastisitas yang tinggi, kemampatan atau perubahan volume yang tinggi, kekuatan geser yang rendah dan potensi kembang susut yang besar.

Proses pembasahan-pengeringan tanah dipengaruhi oleh: perubahan iklim, intensitas hujan, evaporasi, fluktuasi muka air tanah, kebocoran pipa air, sistem drainase permukaan dan pemompaan air tanah. Siklus gerakan kembang-susut pada tanah dapat menyebabkan retakan (cracking), kelelahan (fatigue) dan pengembangan sebagian (differential heave). Tanah ekspansif merupakan salah satu penyebab utama kerusakan lantai dan struktur bangunan (Irsyam, 1993).

Menurut Holtz (1959) beberapa faktor yang berpengaruh terhadap pengembangan tanah antara lain: 1) jenis dan jumlah mineral lempung, 2) kepadatan dan kadar air tanah, 3) kondisi pembebanan, 4) struktur tanah, 5) air pori dan 6) waktu.

Umumnya tanah yang mempunyai potensi mengembang, juga mempunyai potensi menyusut akibat perubahan kadar air. Saat musim hujan tanah ekspansif mengembang, tekanan pengembangan yang dihasilkan dapat mengangkat bangunan di atasnya, sehingga mengakibatkan kerusakan serius pada rumah, bangunan ringan dan perkerasan jalan. Gambar 1 memperlihatkan kondisi tanah ekspansif yang mengalami retak-retak akibat penyusutan saat musim kemarau dan akibatnya pada lantai rumah.

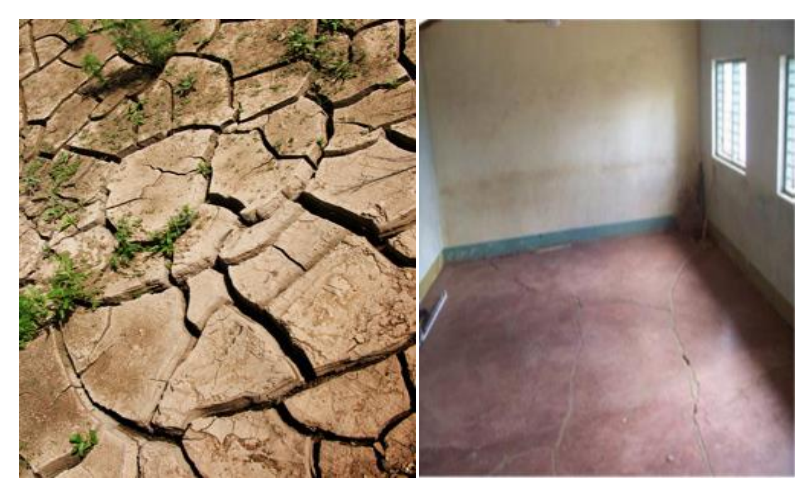

Gambar 1 Tanah ekspansif pada musim kemarau (Zumrawi et al., 2017)

Untuk menanggulangi sifat kembang-susut tanah ekspansif, Mochtar (2000) mengusulkan beberapa pendekatan seperti: 1) mencegah terjadinya perubahan kadar air pada tanah, 2) memberikan beban yang cukup besar di atas permukaan tanah untuk melawan tekanan pengembangan dari tanah, dan 3) memperbaiki sifat yang merusak dari tanah dasar dengan cara stabilisasi.

Beberapa metode untuk mengatasi sifat kembang-susut tanah ekspansif telah dilakukan. Sebagian besar metode ini digunakan di lokasi pembangunan jalan raya, seperti stabilisasi tanah dengan kapur, semen, abu sekam padi dan bahan aditif lainnya. Untuk rumah penduduk, perbaikan tanah ekspansif dilakukan dengan menggunakan perkuatan pada pondasinya. Namun, kendala dana biasanya menjadi masalah untuk sebagian masyarakat. Aplikasi kolom kapur menjadi salah satu cara yang dapat digunakan untuk mengatasi sifat kembang-susut tanah ekspansif. Penggunaan kolom kapur telah diuji oleh beberapa peneliti sebelumnya diantaranya: Al- Saoudi, et al. (2014), Hidayat, dkk (2018), dan Istanto, dkk (2018).

Kapur adalah salah satu bahan yang dipakai untuk stabilisasi tanah. Bahan ini mudah didapat karena banyak dijual di pasaran dan harganya cukup terjangkau. Material kapur ada dua jenis, yaitu kapur mati dan kapur aktif. Kapur mengandung kation kation $\mathrm{Ca}^{++}$dan $\mathrm{Mg}^{++}$yang mampu menetralisir sifat kembang susut tanah lempung/lanau yang besar. Selain itu kapur juga berfungsi untuk merangsang terjadinya proses sementasi antara butiran tanah sehingga membentuk gumpalan partikel yang lebih besar. Hal ini mengakibatkan indeks plastisitas tanah berkurang, dan akan meningkatkan kuat geser tanah.

Kegiatan pengabdian masyarakat ini dilakukan untuk memberikan pemahaman kepada masyarakat mengenai karakteristik tanah ekspansif dan cara mengatasinya. Memberikan penyuluhan kepada masyarakat mengenai penggunaan kolom kapur untuk mengurangi pengembangan tanah ekspansif.

\section{Metode Pelaksanaan}

Kegiatan pengabdian masyarakat dilakukan dalam beberapa tahap, yaitu:

1. Melakukan survei lokasi. Survei lokasi bertujuan untuk mendata kerusakan yang terjadi pada rumah-rumah penduduk. Gambar 2 memperlihatkan kondisi yang dapat terjadi akibat adanya tanah ekspansif. 
2. Data hasil survei selanjutnya dianalisis untuk mengetahui tingkat kerusakan yang terjadi pada rumah-rumah penduduk.

3. Melakukan penyuluhan tentang karakteristik tanah ekspansif dan cara mengatasi kerusakan akibat tanah ekspansif tersebut.

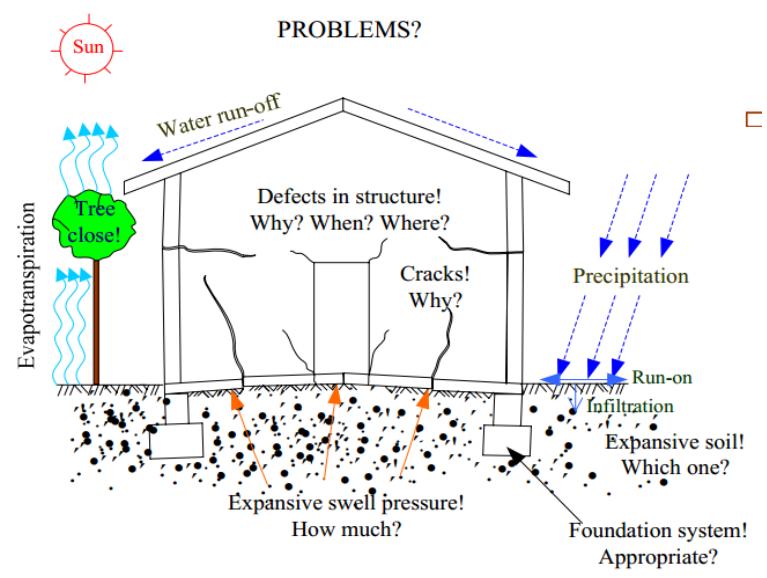

Gambar 2 Bentuk-bentuk kerusakan yang terjadi pada rumah akibat tanah mengembang (Lucian, 2006)

4. Membuat prototype kolom kapur pada salah satu rumah sebagai model.

Kolom kapur dibuat dengan cara membuat lubang berdiameter $20-30 \mathrm{~cm}$ di sekitar lantai atau dinding yang mengalami retak. Kedalaman lubang $75-100 \mathrm{~cm}$, lubang kemudian diisi kapur hingga penuh. Adapun kapur yang digunakan adalah kapur mati, yang banyak dijual di pasaran. Agar supaya mudah bereaksi degan tanah, kapur disiram dengan air. Sketsa kolom kapur yang diperkenalkan ke mitra dapat dilihat pada Gambar 3.

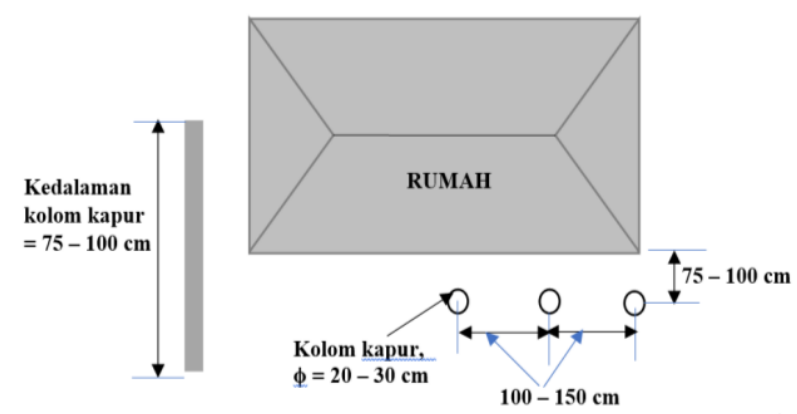

Gambar 3 Skema kolom kapur untuk mengurangi lantai retak akibat tanah ekspansif

5. Agar supaya air hujan tidak tergenang dan masuk ke bawah pondasi rumah, di sekitar dinding diberi lapisan penutup yang kedap air. Bentuk lapisan penutup dapat dilihat pada Gambar 4.

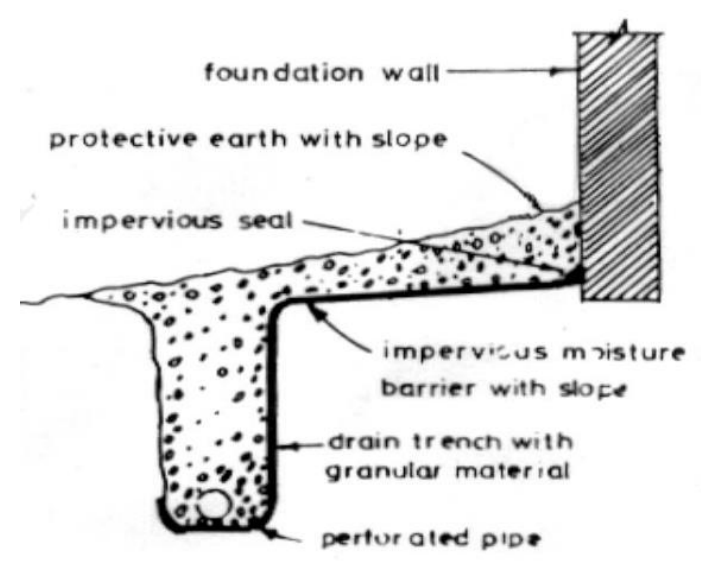

Gambar 4 Perlindungan area di sekitar dinding rumah terhadap genangan air (Arya et a.)

\section{Hasil dan Pembahasan}

Survei ke beberapa rumah penduduk memperlihatkan kondisi berikut:

1. Rumah warga tidak memiliki saluran drainase untuk limbah rumah tangga dan buangan air hujan,

2. Pohon berukuran sedang hingga besar tumbuh di sekitar rumah,

3. Rumah yang dibangun di atas tanah asli tanpa tanah urug mengalami kerusakan berat, sedangkan rumah yang dibangun di atas tanah urug mengalami kerusakan sedang,

4. Rumah yang sebelumnya rusak kemudian direnovasi tanpa perlakuan khusus, akan mengalami kerusakan kembali.

Beberapa rumah di desa Pengengat mengalami kerusakan seperti lantai rumah retak, lantai menggembung, dinding retak hingga dinding terbelah pada pertemuan dinding dengan kolom rumah. Menurut keterangan warga, saat musim hujan tiba sebagian pintu rumah sulit untuk di buka-tutup. Bentuk kerusakan seperti ini dapat dilihat pada Gambar 5 berikut, gambar ini diambil dari rumah salah satu warga di dusun Sebute.

Kondisi yang sama juga terjadi di Kantor Kepala Desa Pengengat. Menurut penjelasan seorang perangkat desa, kantor desa Pengengat 
dibangun pada tahun 1998. Seperti terlihat pada Gambar 6, kerusakan dimulai dari lantai kantor yang retak dan terbelah. Akibat kerusakan tersebut, aula kantor desa Pengengat tidak difungsikan lagi.

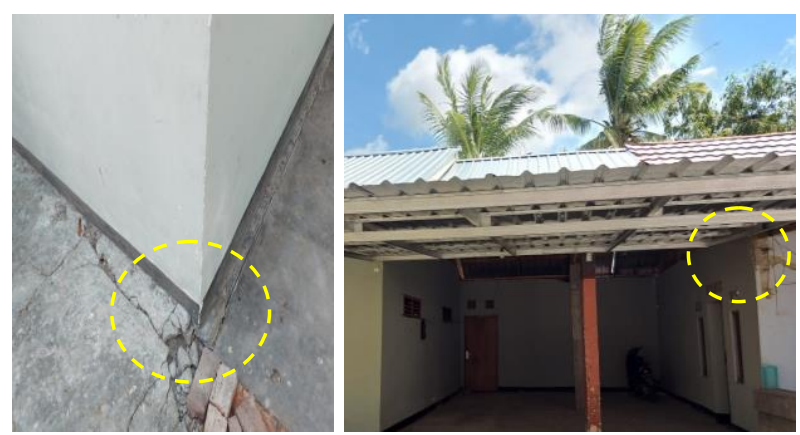

Gambar 5 Lantai dan dinding rumah penduduk mengalami retak-retak (lingkaran kuning)
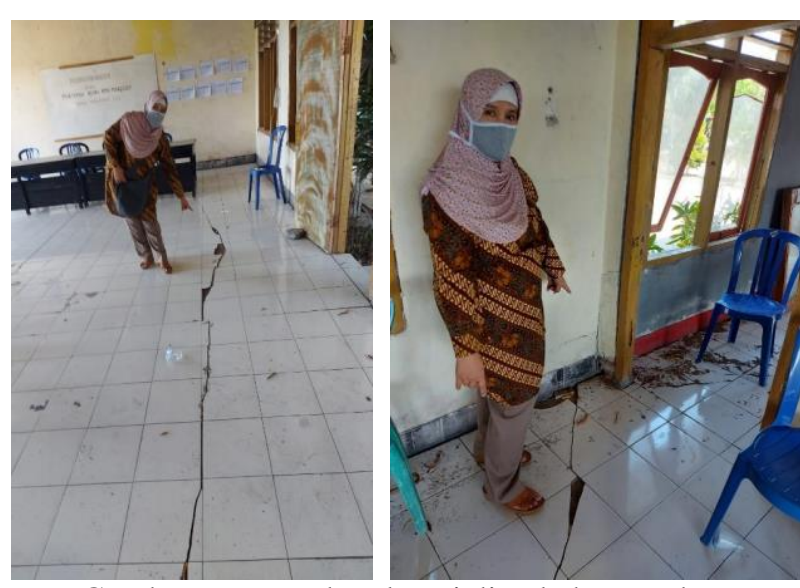

Gambar 6 Kerusakan lantai di aula kantor desa Pengengat

Berdasarkan survei yang telah dilakukan, tim menyimpulkan bahwa:

1. Kondisi tanah tidak padat sehingga air akan mudah mengisi rongga-rongga tanah, akibatnya tanah mudah mengembang,

2. Saluran air tidak tersedia, limbah buangan rumah tangga terus-menerus mengisi rongga tanah,

3. Air hujan tidak tersalurkan dengan baik. Genangan air hujan akan masuk melalui rekahan tanah, akibatnya tanah mudah mengembang,

4. Adanya pohon berukuran sedang hingga besar tumbuh di halaman rumah. Pohon tersebut dapat menghalangi proses evaporasi air yang berada di permukaan tanah, sehingga air tetap berada pada zona aktif. Akar pohon akan menjalar hingga mencapai pondasi rumah. Hal ini mengakibatkan rongga tanah membesar dan air akan mudah masuk ke bawah pondasi rumah.

Hasil survei yang dilakukan selanjutnya dibahas dalam suatu diskusi dengan perangkat desa dan tokoh masyarakat. Gambar 7 memperlihatkan suasana diskusi yang dilakukan. Pada tahap ini tim menjelaskan tentang karakteristik tanah ekspansif, akibat yang ditimbulkannya dan cara mengatasinya. Kegiatan pembuatan kolom kapur untuk mengurangi keretakan lantai juga dibahas dalam diskusi ini. Pembuatan kolom kapur tidak langsung dilaksanakan setelah survei karena kondisi masih musim kemarau dan tanah sangat kering. Pada kondisi ini reaksi kimia antara kapur dan tanah menjadi kurang efektif.

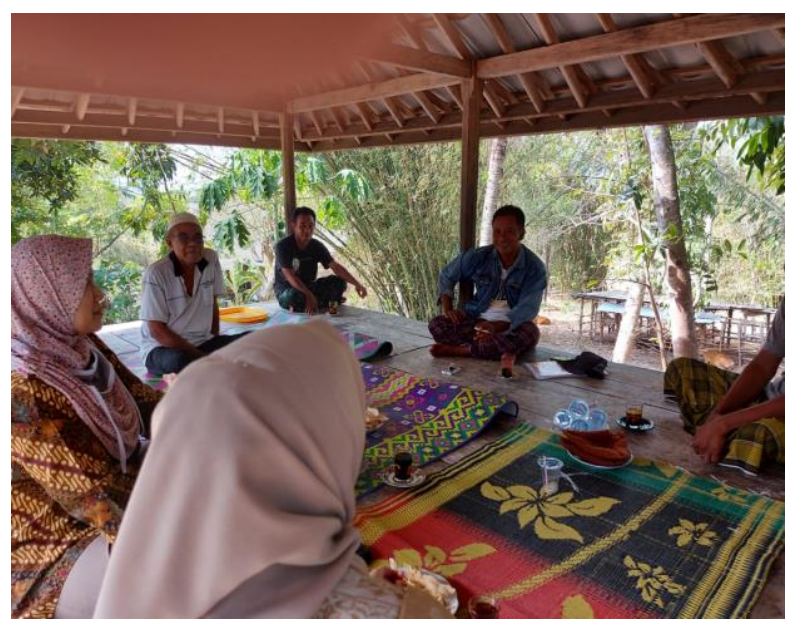

Gambar 7 Diskusi dengan tokoh masyarakat membahas fenomena kerusakan rumah di desa Pengengat

Setelah memasuki musim hujan, kegiatan membuat kolom kapur dilaksanakan di rumah yang telah dipilih. Gambar 8 memperlihatkan tahap penggalian kolom kapur. Kolom kapur dibuat di samping rumah mantan kepala Desa Pengengat. Rumah ini baru direnovasi pada tahun 2019, namun kerusakan masih saja terjadi. Lantai dan dinding rumah retak-retak, di ruang tamu terjadi penggembungan sehingga permukaan lantai tidak rata.

Kolom kapur dibuat di dekat dinding yang retak dengan diameter $25 \mathrm{~cm}$ dan kedalaman $75 \mathrm{~cm}$. Ada tiga kolom kapur yang dibuat dengan jarak antar kolom $1 \mathrm{~m}$. Posisi kolom kapur dibuat di 
bawah cucuran atap agar supaya kolom kapur mendapat siraman air saat terjadi hujan. Gambar 9 memperlihatkan lubang kolom kapur yang telah dibuat.

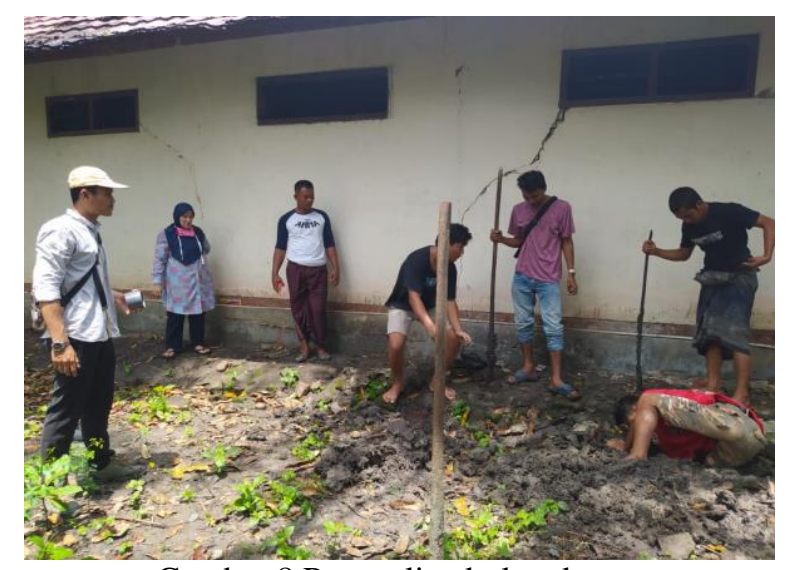

Gambar 8 Penggalian kolom kapur

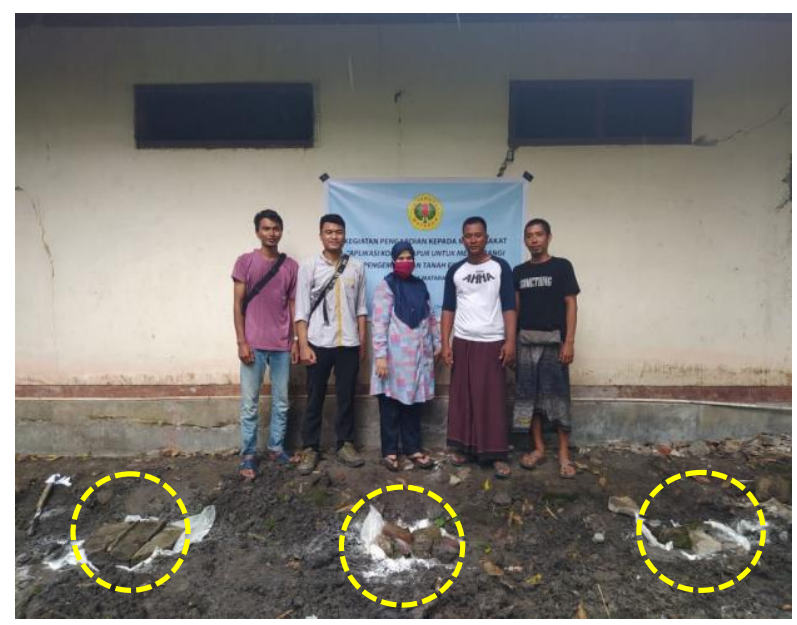

Gambar 9 Kolom kapur yang telah dibuat (lingkaran kuning)

Untuk mengetahui tingkat pengembangan tanah di lokasi pembuatan kolom kapur, di setiap lubang kolom kapur diambil contoh tanah untuk diuji di laboratorium Mekanika Tanah Jurusan Teknik Sipil Fakultas Teknik Universitas Mataram. Hasil uji laboratorium akan dijadikan bahan evaluasi untuk mengetahui keberhasilan kolom kapur yang telah dibuat dan menjadi catatan untuk pembuatan kolom kapur berikutnya.

\section{Kesimpulan}

Dari hasil pelaksanaan kegiatan yang dilakukan di Desa Pengengat, Kecamatan Pujut Kabupaten Lombok Tengah diperoleh beberapa kesimpulan berikut:
1. Sebelum dilaksanakan kegiatan pengabdian masyarakat, masyarakat desa belum sepenuhnya memahami karakteristik tanah ekspansif.

2. Drainase limbah rumah tangga dan air hujan tidak ada sehingga air terus-menerus mengisi rongga tanah dan menjadi penyebab utama lantai dan dinding rumah retak.

3. Masyarakat belum memiliki pengetahuan untuk mengatasi fenomena tanah ekspansif, sehingga meskipun rumah telah direnovasi kondisi rumah masih rusak.

4. Melalui kegiatan pengabdian ini, masyarakat telah memahami karakteristik dan perilaku tanah ekspansif.

5. Kolom kapur yang diperkenalkan ke mitra berdiameter $25 \mathrm{~cm}$ dengan kedalaman $75 \mathrm{~cm}$, dan jarak antar kolom sejauh $1 \mathrm{~m}$.

\section{Saran}

Sebaiknya pembuatan kolom kapur dilakukan lebih awal agarsupaya efektifitas kolom kapur dapat dievaluasi. Masyarakat yang mengikuti penyuluhan seharusnya lebih banyak lagi, untuk meningkatkan kesadaran akan perlunya penataan saluran pembuangan.

\section{Ucapan Terima Kasih}

Ucapan terima kasih kepada LPPM Universitas Mataram, dengan adanya bantuan dana DIPA BLU (BNPB) tahun 2020 memperlancar kegiatan pengabdian yang dilakukan. Ucapan terima kasih juga disampaikan kepada Kepala Desa dan tokoh masyarakat Dusun Sebute Desa Pengengat Kecamatan Pujut Kabupaten Lombok Tengah atas kerjasamanya pada kegiatan ini.

\section{Daftar Pustaka}

Al-Saoudi, N.K.S., Joni, H.H., and Al-Gharbawi, A.S.A., 2014, Single Sand Column Stabilized by Lime Embedded in Soft Soil, Eng. \& Tech. Journal, Vol. 32, Part (A), No.

https://www.iasj.net/iasj/article/99820

Anggara, I.P.H., 2013, Uji Tingkat Mengembang Pada Tanah Lempung Ekspansif di Desa Tanak Awu Kabupaten Lombok Tengah 
Dengan Metode ASTM D4546-90 (A, B, C), Skripsi, Fakultas Teknik, Universitas Mataram, Mataram

Arya, A., Choudhary, A., Khan, A, and Ram, H., Foudations on Expansive Soils, IJERT, https://www.ijert.org/foundations-onexpansive-soils

Fradana, Y., 2014, Analisis Paramaeter Kuat Geser Tanah Lempung Ekspansif Dengan Stabilisasi Fly Ash Berdasarkan Uji Triaksial Unconsolidated Undrained (UU), Skripsi, Fakultas Teknik, Universitas Mataram, Mataram

Hardiyatmo, H.C., 2014, Tanah Ekspansif, Gadjah Mada University Press, Yogyakarta

Hidayat, M.A.S., Setiawan, B., dan Djarwanti, N., 2018, Stabilisasi Tanah Ekspansif dengan Kolom Kapur, Ditinjau Terhadap Potensi Mengembang dan Nilai Indeks Plastisitas, e-Jurnal MATRIKS TEKNIK SIPIL, Maret 2018, $\quad$ hal. $98 \quad-\quad$ 104, https://jurnal.uns.ac.id/matriks/article/view File/36601/23827

Holtz, W.G., 1959, Expansive Clays-Properties and problems, Quarterly of the Colorado Scholl of Mines, Vol. 54, No. 4

Irsyam, M., 1993, Tanah Mengembang dan Stabilisasinya, Jurusan Teknik Sipil ITB, Bandung

Istanto, F.D., Setiawan, B., dan Djarwanti, N., 2018, Pengaruh Kolom Kapur Terhadap Potensi Mengembang dan Peningkatan Kekuatan Tanah Ekspansif Dengan Pengaliran dari Tanah ke Kolom, e-Jurnal MATRIKS TEKNIK SIPIL, Maret 2018, hal. $143 \quad-\quad 149$, https://jurnal.uns.ac.id/matriks/article/view/ $\underline{36605 / 23831}$

Kharvarazy, 2010, Pengaruh Stabilisasi Tanah Lempung Ekspansif Dengan Penambahan Trass Dan Kapur Terhadap Nilai CBR,
Skripsi, Fakultas Teknik, Universitas Mataram, Mataram

Lucian, C., 2006, Geotechnical Aspects of Buildings on Expansive Soils in Kibaha, Tanzania: Preliminari Study, Thesis, Royal Institute of Technology, Stockholm, Sweden.

Mochtar, I.B., 2000, Teknologi Perbaikan Tanah dan Alternatif Perncanaan pada Tanah Bernmasalah, Jurusan Teknik Sipil FTSP ITS, Surabaya.

Ramdhani, A., 2014, Pengaruh Penggunaan Cerucuk Dengan Pemasangan Secara Horisontal Terhadap Kuat Tekan Tanah Lempung Lunak, Skripsi, Fakultas Teknik, Universitas Mataram, Mataram

Shaheema, S., and Aparna, S. J., 2016, Effect of lime Column on the Geotechnical Properties of Kuttanadu Soil along Radial Directiion, IJETT, Vol. 39, No. 5, http://www.ijettjournal.org/archive/ijettv39p244

Wibawa, L.M.H., 2013, Pengaruh Penggunaan Cerucuk Terhadap Kuat Tekan Tanah Lempung Lunak, Skripsi, Fakultas Teknik, Universitas Mataram, Mataram

Zumrawi, M.M.E., Abdelmarouf, A. O., and Gameil, A.E.A., 2017, Damages of Building on Expansive Soils: Diagnosis and Avoidance, International Journal of Multidisciplinary and Scientific Emerging Research, Vol. 6, No. 2. https://www.researchgate.net/publication/3 17032307_Damages_of_Buildings_on_Exp ansive_Soils_Diagnosis_and_Avoidance 